\title{
Review on Chinese Sport Industry and Corresponding Management and Financial Methodologies: Opportunities and Prospects
}

\author{
Yingwei Zhao ${ }^{\text {a, }}{ }^{*}$, Lina Zhu ${ }^{\text {a }}$ \\ Qingdao University of Science \& Technology, Qingdao 261000, China \\ azhaoyingwei6666@126.com
}

Keywords: Chinese Sport Industry; Management and Financial Benefit; Opportunity and Challenge.

\begin{abstract}
With the bursting development of the market economy in China, the importance of consumer demand to economic growth is becoming more and more apparent. Currently, our country sports management major has different types of colleges and universities set up breakthrough single the construction mode of public utility management profession, but sports management major setting discipline theory basis is still exist many problems. Through what constructs the definition speculative sports, physical education and sports between total concepts as well as the dialectical relationship between discipline and profession. Pointed out that the sports management is set to the pedagogy or public utilities management under the discipline of a professional direction. Our review will help us construct a more effective and flexible module to develop the harmonious sport industry.
\end{abstract}

\section{Introduction}

Sports management subject was born in the United States in the 1930s, the subject is a branch of management science, belongs to the department of management, it also is an important branch of the discipline of sports science. For this young subject, timely and accurately summarize the latest progress in the study of sports management at home and abroad, especially in theoretical innovation promotes our country sports management have important academic value. Along with our country sports enterprise and accelerating the industrialization process, the practice of sports management field, it extends far beyond the original sports public utilities management category [1-2]. Was established in China's socialist market economic system reform of public utilities in the early (sports) professional discipline foundation management, talents cultivation orientation and course system setting mode has been gradually cannot satisfy the rapid development of China's socialist market economy requirements [3]. From the perspective of the relationship of subject and professional, discipline is the foundation of professional knowledge system construction. And professional is a discipline to assume the carrier of society needs talents cultivation, accordingly. Professional disciplines of sports management in-depth academic review, analyze the internal logic relationship between the professional and discipline. Help of sports management professional will accurate positioning its talent training goal and specifications. Help to provide theoretical basis for the professional course system setting. Can also for professional development to adapt to the social development, reasonable selection and organization discipline knowledge, form a new direction to lay the foundation of talent cultivation [4]. Decided to sports development level of economic development level, that is to say, sport is developed with the economic and social development. Original sports is linked with people's labor, when the development of social labor productivity which makes it possible for such activities as fitness, health, sports and phase separation, people's productive labor and become independently existing forms [5]. In the $1950 \mathrm{~s}$, with the revolution of science and technology as the forerunner, the economy has rapidly developed in many countries. Fast growing economic strength enhances the world economic system. People's income and living standards improve, people's leisure time increasing, inevitably to the spiritual and cultural life and sports entertainment activities, higher requirements are put forward. In order to adapt to the requirement from the country to the enterprises and institutions are actively increase the sports venues and facilities, to meet people's need for sports. 
The sports market in China is from the planned economic system to develop in the direction of socialization and industrialization and it is lack of the support of capital accumulation, the lack of professional management and the lack of science and technology innovation [6-7]. The lack of policies and regulations of specification after joining the WTO, the opening up of market and the entry of foreign capital will make these unfavorable situations resolved quickly. In this paper, we conduct review on Chinese sport industry and corresponding management and financial methodologies. The following sub-sections, we will summary the opinions in detail.

\section{Our Review on Chinese Sport Industry}

The Overview of the Sport Industry and Physical Education (PE). The discipline structure reflects a discipline of the relationship between each component. From the perspective of the features of sports products, sports products by Paul from competitive and exclusive features for classification can be divided into four categories: private products which can charge and pure public goods and public resources, thus, the production organization form can be divided into two categories: subject construction mode and the public management and business management. Wuhan sports college in 2007 was the first to declare in domestic sports colleges and universities and set up a leisure sports (management) professional, make its major setting range from the private to the public product and public administration for industry and commerce of the two disciplines; From the point of management of resources, an organization's resources, including people, money, material, information and time, the Shanghai sports institute from the perspective of resource management set up professional sports information management: at the same time. From the management level, management activities can be divided into macro and micro level. Beijing sports university which opened the sports industry management this paper management. Therefore, from different colleges and universities set up the development trends of sports management related field. It has gradually broken through the sports management under different from sports science or public education under the management of major setting mode. Sports management practice areas rich in content and other management practices have a significant difference between the two. It is not conducive to the development of the discipline of sports management for the following reasons. First, in the problem of solving for the purpose of sports management practice subject orientation which can produce a kind of pragmatism orientation need to be solved. Sports will be as an attachment to the other disciplines of management disciplines and could not form the driving force of its development. Management is both a science and art. Have the feature of "artistic quality" of the sports management is mainly due to the problem of the "people" of the. Physical activity as a person's life activity the moment of purpose, needs, desires, and needs, and so on. Obviously feeling is different from other social activities. Therefore, mining activities of sports act as a subject of people's needs. Sports management is an important task of subject construction. Third, if from scientific point of view, is a mature discipline need to clarify the different between disciplines knowledge kernel. Standing in sports is the position of a person a kind of life activity carefully distinguish the subject category of sports science can be found. Undertakings of physical culture and sports and sports industry, mass sports and competitive sports, sports teaching and sports training is, in fact, principles of management and application of basic methods in these areas. Because. Regardless of these management activities is public or private interest sex which is a high level or general fitness activities, administrative management or business activities. Can find humanism, efficiency, responsibility and ethics which runs through the basic principle such as always, can also be found that the administrative, economic, legal, and different proportional use of propaganda and education management methods, planning, organization, coordination, command and control, and other functions of management as the main management cycle. There are many teachers in the school sports and school sports management teaching. When found that the content of the two courses there are many problems of crossing, overlapping.

The Sport Finance and Benefit in China. After 20 years of reform and opening up in China, production capacity has been changed. Since the mid of the 1990s, after the market competition, 
merger and integration, the situation of China's market evolution, emerged a large number of famous brand enterprises. Such as Li Ning brand sportswear, Jianlibao drinks and double happiness sporting goods and so on, have a certain competitiveness, has captured a large market share, become the industry leader. Although foreign manufacturers took a fancy to China's huge market, but it is even in advanced countries such as the United States are scared of the competitiveness of Chinese products, often anti-dumping charges for China's product is a case in point. It should be said that foreign goods is not a disaster, in normal market competition both at home and abroad, China's enterprises still can win on labor-intensive products, increase the competitiveness of high technology content of products at the same time. The foreign product of the competition is to promote China's industrial progress. All kinds of trade agreements in the WTO, in addition to the sports industry of ontology, there is no other specific agreement, the market potential of sports in China has been favored by foreign mediation group or multinational company and existing part into the market in our country, therefore, should take in a planned way to gradually open policy, the sports market of the WTO rules to protection of the industry. When the industry is threatened, can protect, but protection is time, can't always use, must develop its own industry. In addition, the means of protection can be varied using standard with a lot of things is can be done through normal channels. Sports industry at the beginning stage in our country, many things will depend on you, but we can't wait for successful model appear to act again after, must accelerate the pace of industrialization of sports practice, bold practice, only practice can really promote the rapid development of sports industry in China. For all kinds of sports clubs, there has been a gradual developing it into enterprise management or independent sports business entity. Sports operators are by investing in production and provide products and get profit operators. The current should be vigorously cultivate sports operators. First to advocate and promote the development of sports operators as investment, investment main body should be diversified, should implement the state, the collective, the individual and combined use of foreign capital. Next, want to cultivate sports operators marketing ability, establish the market idea and take the market as the guidance. Targeted production and provide sports products. Sports class should have a different product, such as exclusive golf club, mid-range of tennis, bowling club, etc., there are also sports products which can meet the sports fan, not out of the spending power of the masses in our country. In the figure 1, we illustrate the growth rate of the sport related profit for the government.

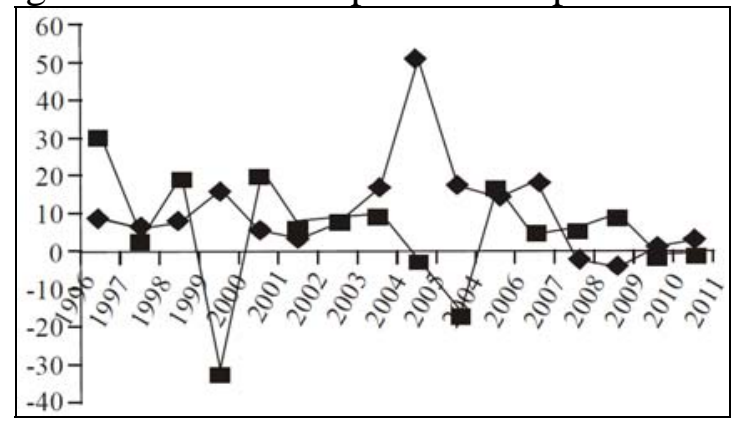

Figure 1. The Growth Rate of the Sport Related Profit

The Sport Management Policy in China. With the rapid development of the socialist market economy in our country and the continuous improvement of people's living standard. Sports undertakings and industry gradually become an important change in the national economic structure transformation. Our country sports management discipline and specialty construction in order to adapt to the development of the society. In both theoretical research and practice field and professional Settings has been far beyond the scope of pedagogy. Therefore, accurate positioning the sports level of subject status is the key to healthy development and construction of sports management discipline. Sports management discipline's own structure should be combined with the feature of sports science disciplines. In management science, the four axis build four dimensional space for the direction of the professional basis, namely function axis (plan, organize, control, decision making and innovation), content (sports administration, sports industry and sports management), product (from private and public to the pure public product) and hierarchical axis (macro and micro sports management). The human nature assumption in management is to live in the 
reality. Have their values, preferences, and feelings of personality. Management determines the nature of the object of the managers and managers are role characteristics, therefore, management pay more attention to human nature, the natural attribute and social attribute of men at the same time into the study scope. Management that people not only have universals in human nature. At the same time to accept human nature has the characteristics of personality. At the same time. Also believe that the change of social environment of management can lead to the change of human nature. Therefore, the human nature assumption in management is more emphasis on specific, more complex and changeable complex. Determine the character of the human nature assumption of management paradigm of management science is an open knowledge system, any is helpful to solve the problem of management knowledge. No matter what it belongs to the subject. Can be absorbed in reference to the management research on people's behavior, can from a wide variety of disciplines, through its methods and research results to qualitative and quantitative analysis of complex management activities. Therefore, management of the sport industry help us construct a more effective and flexible module to develop the harmonious sport industry.

\section{Summary and Conclusion}

With the bursting development of the market economy in China, the importance of consumer demand to economic growth is becoming more and more apparent. Sports management subject was born in the United States in the 1930s, the subject is a branch of management science, belongs to the department of management, it also is an important branch of the discipline of sports science. Entered the new century, our country national economy continued rapid growth, people's income and economic living standards greatly improved, people to demand higher sports entertainment activities. According to the forecast, annual output value of the national economy growth will remain at 7. 8\%, residents' income growth, by an average of 3.84\% of farmers, urban residents' average $5.32 \%$. To 2018 , the per capita GDP will reach $\$ 2,516$, to complete the task of industrialization which will reach about $\$ 5,400,2030$, into the level of moderately developed countries, about 2040 years into the ranks of rich countries. The 21st century will be the period of our country sports industry development, maturity and prosperity. In this paper, we conduct review on Chinese sport industry and corresponding management and financial methodologies. We believe our work will help us get a broader insight perspective of Chinese sport industry.

\section{References}

[1] Sen Z, Jiahong W. Optimization the management path of Chinese leisure sport industry -Inspiration from United States [J]. Sport Science Research, 2014.

[2] Xiao-fei L, Liang L, Dept S. Concept, Characteristics and Classifications of Traditional Chinese Sports Industry of Ethnic Minorities in China [J]. Journal of Sports Adult Education, 2014.

[3] Bing-song Z. Fitness Positive Energy: Discussion on the Character of Chinese-style Fitness Culture Industry [J]. Journal of Guangzhou Sport University, 2014.

[4] De-Hao M, Liu J. Influences of the Decreasing Proportion of Chinese Working-age Population on Sporting Goods Industry [J]. Journal of Chengdu Sport University, 2014.

[5] Yi-fan A, University J. Our Sports Industry Development Present Situation and Countermeasure Research [J]. Journal of Inner Mongolia University for Nationalities (Natural Sciences), 2014.

[6] Gang W, Lian-peng C, Guo-zhi W. Research on the Cross-area Integration and Development of Chinese Martial Arts and Animation [J]. Journal of Nanjing Sport Institute (Social Science), 2014.

[7] Sun P, Cao R, Wu X. Research on Allocation Issues of Mass Sports Resources in Post-Olympic Period in China [J]. Proceedings of the 2012 International Conference on Cybernetics and Informatics, 2014. 